\title{
Shortage of health workers in the Malawian public health services system: how do parliamentarians perceive the problem?*
}

\author{
Adamson S. Muula \\ Department of Community Health, University of Malawi College of Medicine, Malawi \\ Address for correspondence: Department of Community Health, University of Malawi College of \\ Medicine, Private Bag 360, Chichiri, Blantyre 3, Malawi. Email: amuula@medcol.mw
}

\begin{abstract}
SUMMARY
The quality and quantity of health care services delivered by the Malawi public health system is severely limited, due to, among other things the shortage of adequate numbers of trained health care workers. In order to suggest policy changes and implement corrective measures, there may be need to describe the perceptions of the legislature on how they perceive as the cause of the problem, which could be the solutions and an evaluation of those solution. In this paper, I present the finding from a qualitative study of Hansards (official verbatim record of parliamentary speeches) analysed by discourse analysis. Parliamentarians identified the shortage of health workers as resulting from death, retirement and brain drain to other countries mostly the UK, Saudi Arabia and South Africa. Training more health workers, training new but lower cadres of health workers not marketable to the outside world, improving the working conditions and remuneration of health workers are suggested as some of the solutions. Even without the brain drain of health workers to other countries, Malawi's health sector personnel numbers are not adequate to serve the needs of the country. Relying on training more health workers in the numbers normally produced from the prevailing training institutions is unlikely to remove the shortages.
\end{abstract}

[Afr J Health Sci. 2006; 13:124-130]

*Published online before print

\section{Introduction}

The Malawian public health system is grossly compromised in not having adequate health workers by far. The country with a population of 11 million people has just about 252 doctors, 338 clinical officers, and 601 medical registered with the Malawi Medical Council in 2003 [1]. These are distributed in mission, public and private health facilities and in research organizations. The public health system is constrained further by the HIV and AIDS pandemic, which has resulted in increased attrition of health workers due to death and ill-health in a situation of increased need as the country scales-up various HIV/AIDS intervention programs [2]. Malawi has one medical school $[3,4]$ with an annual output of about 20 medical doctors. First year intake of medical students have just been increased to between 45 and 60 in the past two years. Most of the clinical, including operative duties are performed by clinical officers [5]. Medical assistants, a cadre lower than clinical officers are not permitted to perform surgical roles but this is the cadre that is posted to mostly rural health centers. Most of the public health systems in southern Africa are suffering from shortage of health personnel resulting from a combination of the following factors: migration of health workers, high attrition due to ill-health and death, mostly as a result of AIDS, migration from the public sector to private sector (research centers and HIV/AIDS non-governmental 
organizations). In Malawi, there also seems to be a lack of interest among young school leavers towards training in health professions (Personal communication, Fresier Maseko, Head of Sciences, Malawi College of Health Sciences).

The brain drain of health workers from Africa to overseas countries has received enormous attention lately. The reasons for the loss of health workers from Africa (the push factors) include poor remuneration and working conditions, while the attracting factors (pull factors) include better working conditions and remuneration in developed countries. Possibilities to obtain higher academic and professional qualifications may also be influencing health workers from Africa to leave and work overseas.

While various papers have been published on people's perceptions and the perceived reasons for the brain drain and shortage of health care workers in southern African countries, [69] I am unaware of any studies that have reported the perceptions and discourse of members of parliament in the sub-region. Parliamentarian influence and set policy deliberate to allocate national budgetary requirements and may reflect the perceptions of the general community.

As the scaling-up of antiretroviral therapy was being executed, the shortage of health human resources was identified as one of the major impediments to making ARVs widely accessible to the majority of the affected people. This study was therefore conducted to describe the discourse of MPs in the Malawi National Assembly between 1999 and May 2004, as this has implications to solving the health human resources crisis affecting the country.

\section{Materials and Methods}

This was a qualitative study utilizing Malawi National Assembly's Hansard for the period 1999-2004 as sources of data. The Hansard is the official published verbatim report of the proceedings of a parliamentary body. Copies of the Hansard were obtained from the National Assembly and were manually read to identify sections where discussions on HIV and AIDS, reproductive health and condoms were made. The speeches were later analysed using discourse analysis to identify themes and patterns of thought. The analytic approach is within the domain of social psychology operating at the interface between ethnomethodology and conversation analysis [10-13]. The limitations of using Members of Parliament as study subjects include the fact that it may not be possible to strictly determine whether what was said were their own thought or they were speaking on behalf of others, e.g. their constituents. However, as these speeches are being made in the National Assembly, such may have far reaching consequences in terms of policy, although not necessarily practice.

Surveys aimed to study perceptions of a particular group of people suffer from the fact that the study subjects are not in the naturalistic environment i.e. they may try to conform in reporting what they think the researcher wants to hear. This study utilized normal parliamentary conversations and may not be affected by such biases. However, as MPs know that they are being watched, the temptation to impress and be controversial may play out in different individuals. Also, not all MPs contribute evenly to the discussions.

\section{Results}

\section{The gravity of the situation}

The Malawi public health services delivery system is severely limited by the shortage of health care workers. The shortage has also affected the denominational health facilities mostly run by the Christian Health Association of Malawi (CHAM). In 2000, the Minister of Health said:

"The most overriding problem now facing the health sector is that of human resources. Of the 13,629 posts established in the sector, only 10,697 or 78 percent are filled. Of the 7,380 established in CHAM, only 4,104 Or 56 percent are filled."

It is just not one cadre of health workers that has been affected. The shortages are even present when one looks at not the present requirements, but rather on posts established many years ago.

"In almost all cadres, from physicians to nurses to clinical officers and technical support staff, shortages are common place 
and in many cases, critical. Thus for example, while we have established posts for medical assistants, only 391 of these are filled, and 709 posts are vacant. Of the 462 established posts for clinical officers, only 241 are filled."

“...the World Health Organisation says that Malawi should have at least and I emphasize, at least 870 doctors for a population of its size. We have in fact around 187 including...."

Even when infrastructure is available for sites where health facilities could be opened, the buildings are not opened to serve as health facilities. The Ministry of Health for instance owns the old building at Salima, a lake district of Malawi, which had housed the old hospital. After a new hospital was constructed far away from the old site, communities around the old hospitals felt the buildings could still be used as a health facility. The Minister of Health however said:

"...The only impediment at the moment is identification of relevant personnel to man the post..."

"My Ministry is aware that MASAF has constructed a dispensary at Kadango Dispensary and that facility is not yet operational. In fact, there are a number of few health facilities, which have been constructed in Mangochi District with support from $M A S A F$ and have not yet started delivering the services to the Community. The delay in starting to deliver the services at these new health facilities is due to shortage of trained health personnel. To cut the problem of shortage of health personnel, my Ministry is currently training various health personnel at various health training institutions in the country and upon completing their course, we will employ and deploy and allocate them to new health facilities which have not started delivering services to the community due to shortage of trained health personnel such as Kadango Dispensary. ...the Honourable member may also wish to note that as an extreme measure, a Health Surveillance Assistant has been deployed at Kadango
Health where he is delivering some basic health services..."

The Malawi Social Action Fund (MASAF) is a World Bank funded development programme, which among other issues funds the construction of health facilities with the support of community who contribute labor.

Malawi's shortage of health personnel is likely to be there for many years to come.

"We estimate that our 22 district hospitals alone need 3,850 nurses, we have only 500 nurses. If you consider the nursing needs of the country.... we estimate that we are short of around 6,000 nurses. If we continue to train 400 nurses each year, it will take us 15 years to catch up with what we need for the year 2002. Of the 1,055 medical assistants posts, only 391 are filled and of the 462 clinical officers posts, only 241 are filled."

In some cases, where a health facility would open on the posting of one health worker such as a nurse, these health facilities may not be opened for years, for lack of personnel. In one circumstance, a nurse was posted. She resigned from government service before assuming her new post.

"...Unfortunately, this particular nurse
resigned before she took up her
assignment at..."
The Ministry of Health is rather desperate as it tries to allocate the few available health personnel to an increasing number of health facilities. When pressed to assure an MP whether the ministry would post a health work, the minister said:

"My Ministry will transfer someone from somewhere to go to...."

As for the shortage of nurses in district hospitals, the Minister of Health summed up the situation.

"The Management Change Agency Report for the Ministry of Health and Population indicates that our district hospitals should have an average of 90 nurses each. No district hospital in the nation has more than 20. We need at least 70 pharmacists for the sector, we have 7." 


\section{RESEARCH ARTICLE}

\section{Causes of health worker shortages}

Members of Parliament (MPs) discussed on the reasons for the shortages of health workers in Malawi. The Minister for Health ascribed the shortages due to natural causes such as death and retirement.

“...my Ministry is facing serious shortages of trained medical personnel.

This is due to the high death-rate and retirement..."

"Wastage in the sector, particularly among professional cadres, is estimated at around 3 per cent per annum and death is the most significant cause."

“.. my Ministry is facing critical shortage of trained staff in all facilities. This shortage is a result of death, retirements and natural attrition rates..."

The Minister did not go into details as to why there were high death rates amongst health care workers. However, it is reasonable to suggest that many of the deaths are likely to be as a result of AIDS. Deaths from chronic conditions are common among teachers and health workers in Malawi. Most of these deaths are likely to be due to HIV/AIDS.

At another meeting, an MP said:

"Most of the doctors who work under this Ministry, they are getting inadequate salary. As a result, most of them are crying."

Over the past decade, Malawi has witnessed the growth of the private health sector and establishment of multinational research organizations. Health non-governmental organizations (NGOs) mostly working in the HIV and AIDS prevention and care services have also been established. These are attracting health workers away from the private sector. Many nurses are also migrating to other countries.

"The growth of the private sector which offers very attractive remuneration packages, combined with non-competitive government salaries, is causing haemorrhage from the sector. Another troubling phenomenon is also appearing, and that is the raiding of Malawian nurses by countries such as the United Kingdom, Saudi Arabia and South Africa."

While there are identifiable problems that may result in health workers leaving the country for others, it is sometimes perceived that even when working conditions are improved, some health workers would still leave.

"...indeed it is true that our nurses are leaving Malawi for greener pastures, especially in the United Kingdom. The problem is not only here in Malawi, but it is a problem in all SADC countries where nurses are leaving their countries for greener pastures in the United Kingdom or North America. The issues are multifactorial. One is, indeed, low salaries, but also as human beings, they would like to venture to go, like most Malawian would like to venture to go work in other countries."

It was also suggested that young nurses may leave the public service because of ill-treatment by those they find at their work stations.

"...but these highly qualified nurses

going to hospitals to be administered and looked upon by senior old nurses who are harassing them..."

This is possible especially where younger nurses who have degrees are posted to health facilities with less trained nurses. As a result the new comer, by virtue of his or her academic and professional qualifications, may assume a higher rank than the much older, long-stayed but less qualified nurse. Such may be a source of interpersonal conflict.

\section{What are the Solutions?}

Several solutions have been suggested to increase the number of health workers in Malawi. One cadre of health workers that has been introduced is the auxiliary nurse. This cadre receives bedside training for a period of one year under a qualified nurse. The Malawi Nurses and Midwives Council (MNMC) does not recognize this cadre of health workers, complaining that nursing standards may deteriorate by introducing such a lower cadre. 
The Ministry of Health however argues that this group will contribute to service provision while on training and on qualification, they are unlikely to migrate to work in other country. The President of the Republic in his opening speech of the National Assembly said:

"The training of Auxiliary nurses has been initiated. This group will operate under direct supervision of a trained nurse and will be responsible for such services as washing of patients, bed changing and general patient assistance, among other. Approximately 20 such nurses are trained in each district hospital."

Other than the introduction of a new cadre of health workers who are perceived as not marketable to the outside world, the Ministry of Health reported intentions to train more health workers.

"My Ministry is making efforts with the assistance of donors to train more medical personnel including nurses, doctors and medical assistants."

However, training of more health personnel alone was perceived as inadequate to solve the root causes of why health workers were inadequate in Malawi. “

"...My concern is in respect of the action he has proposed on training. These are vis a vis the way our nurse are disappearing to the United Kingdom, Saudi Arabia and South Africa. Training is very expensive and he has put very elaborate scheme of training more nurses. These will again be taken away by United Kingdom, Saudi Arabia and South Africa because the kind of pay and conditions of service we offer our nurses."

Such intentions to train more do not always materialize as the training institutions to be functional; do require resources that the ministry may not be able to provide. In any case, all the training institutions for health workers (medical assistants, clinical officers, doctors, laboratory and radiography) are autonomous, not run by the Ministry. At some point, the main training college for clinical officers and medical assistants remained closed for over 7 months.

"...the College of Health Sciences is not yet opened for the first and second year students. Now if he clinic is lacking staff and the college is not operational, how can we have staff?"

Perhaps the closer to the truth situation is what the Minister for Health said:

"...Even if moneys were available, which is not, the country doesn't have the capacity to produce nurses, clinical officers and medical assistants to adequately staff those facilities we already have."

Malawi seems to need more than just money to train its health human resources. It also needs trainers who are not readily available in the country. An MP suggested that a "crash programme" for the training of health workers be implemented.

"...I just wonder why it is a problem for the government to come up with a crash program with a view to increasing the enrolment of nurses in training schools and colleges. The government did that in 1994/96 and 1996 with the Ministry if Education, Sports and Culture where is came up with some sort of a crash program for teachers".

In 1994, after change of government in Malawi, the new administration implemented a universal free primary school program. Over 1.2 million children were added to the primary school list that year. However, the education sector had inadequate number of teachers. As a solution in the short to medium term, school leavers with no training in education were recruited to teach. These recruits were trained on the job with a few weeks each year of class work. This was the "crash programme".

Since poor remuneration and work conditions of health workers in the country have been identified as reasons why health workers leave, it makes sense to suggest improvements in pay packages and other incentives. 
"The Ministry is indeed experiencing an acute shortage of medical assistants and nurses. This shortage applies to almost all cadres in the health sector. The ministry is taking up appropriate measures to address this human resource shortage. The measures include the introduction of incentives to health workers in order to retain the ones we have and to encourage others to join the sector."

Despite having said that a few years ago, the incentives referred to above are yet to be worked out. Possibly, the minister was speaking just to appease the listeners.

Some suggestion is whether bilateral partners to Malawi such as the UK could support the development of health human resources in Malawi:

"...Is there any way in which those countries like Britain, who give us technical assistance can ensure that instead of paying our nurse low pays that kind of technical assistance is meant for our nurses to top up their salaries or give incentives so that they stay. Because we spend a lot on training them and they disappear going to UK. I think we will still go on begging and begging. We train nurses, they will go and disappear."

Another suggestion that was made to solve the health worker shortages was to employ retired persons. This works to some extent especially when the relatively very old people are concerned. As for middle aged persons, they would rather get employment in the private sector than returning to the civil service.

In order to retain public servants at senior levels, the government of Malawi introduced higher remuneration for the four top levels of the civil services. The Ministry of Health on its part said such a policy would assist in keeping experienced doctors within the public service. This argument was not convincing to one MP who said:

"I was asking that question with respect to performance related contracts and I am not sure if he can convince this House that improving the salaries of the top levels of the Civil Service, improve the performance of the entire Civil Service."

\section{Discussion}

The Malawi health services delivery system is severely constrained by the lack of health personnel. Parliament identifies the following as the causes of such shortages: migration of health workers especially nurses to the United Kingdom, Saudi Arabia and South Africa, death and retirement. While the increased mortality as a result of HIV/AIDS could disturb the situation, retirement should not normally do that to any great extent, unless the retirement age were adjusted downwards which is not the case. Our present situation suggests a lack of adequate human resources planning where HIV/AIDS and retirements would have been factored in. Malawi has experienced AIDS for over 20 years now such loss of health workers should have been anticipated.

Unless drastic measures are effected, the shortage of health workers is likely to be experienced in years to come, at even a higher rate. This is likely because the need for nurses abroad continues to grow, and training posts have not increased substantially. It would appear that the great emphasis put on brain drain as the reason for our human resources situation, is just one part of the story. Malawi has less than adequate numbers of doctors and nurses. There is no dermatologist, only three pathologists, one radiologist, no oncologist, and no ear and nose specialist. The reason these specialists are not available has nothing to do with brain drain. It is just that they have not been trained.

The use of auxiliary nurses or substitute health workers, defined "as workers are cadres who take on some of the functions and roles normally reserved for internationally recognized health professionals such as doctors"[14] has been suggested as reasonable option for a country facing severe human resource shortages such as Malawi. The high death rates of health workers, [15] likely from HIV/AIDS require specific interventions tailored to this sector of society.

MPs seemed to understand the shortages of health workers in Malawi. However, there is little indication to suggest that corrective measures of substantial scales are being implemented. While the developed countries receiving Malawian health workers could 
contribute to the health budgets of the country, it will be prudent also if these resources are geared also towards efforts to retain staff.

\section{Acknowledgement}

This study was funded by TROCAIRE (Ireland) through the Malawi Health Equity Network (MHEN).

\section{References}

1. Malawi Medical Council. Register of Medical Practitioner and Para-medicals 2003. Malawi Medical Council, Lilongwe, Malawi, 2004

2. Muula AS. Ethical and programmatic challenges in antiretroviral scaling-up in Malawi: challenges in meeting the World Health Organization's "Treating 3 million by 2005" initiative goals. Croatian Medical Journal. 2004; 45: 415-21

3. Muula AS. The Malawi College of Medicine coming of age (Central African Journal of Medicine. 2002; 48:14-16). Central Africa Journal of Medicine. 2003; 49: 43-4

4. Dahlenburg GW. Letter from ... Malawi: the first year of the College of Medicine of the University of Malawi. Tropical Doctor. 1993; 23: 4-6

5. Fenton PM, Whitty CJ, Reynolds F. Caesarean section in Malawi: prospective study of early maternal and perinatal mortality. British Medical Journal. 2004; 327: 587

6. Habte D, Dussault G, Dovlo D. Challenges confronting the health workforce in sub-Saharan Africa. World Hospital \& Health Services. 2004; 40:23-6,40-1

7. Muula AS, Mfutso-Bengo JM, Makoza J, Chatipwa E.The ethics of developed nations recruiting nurses from developing countries: the case of Malawi. Nurse Ethics. 2003;10: 433-38

8. Marchal B, Kegels G. Health workforce imbalances in times of globalization: brain drain or professional mobility? International Journal of Health Planning \& Management. 2003; 18 Suppl 1: S89-101

9. Narasimhan V, Brown $H$, Pablos-Mendez A, Adams O, Dussault G, Elzinga G, Nordstrom A, Habte D, Jacobs M, Solimano G, Sewankambo $\mathrm{N}$, Wibulpolprasert S, Evans $\mathrm{T}$, Chen L. Responding to the global human resources crisis. Lancet. 2004; 363: 1469-72
10. Slembrouck S. Discourse analysis. Accessed from: http://bank.rug.ac.be/da/da.htm

11. Selikow TA. "We have our own special language." Language, sexuality and HIV / AIDS: a case study of youth in an urban township in South Africa. Africa Health Sciences. 2004; 4:102-108.

12. Leishman JL. Talking the talk: a discourse analysis of mental health nurses talking about their practice. International Journal of psychiatric Nursing Research. 2004; 10:113645.

13. Cheek J. At the margins? Discourse analysis and qualitative research. Quality Health Research. 2004; 14:1140-50.

14. Dovlo D. Using mid-level cadres as substitutes for internationally mobile health professionals in Africa. A desk review. Human Resources for Health. 2004, 18: 7

15. Harries AD, Hargreaves NJ, Gausi F, Kwanjana JH, Salaniponi FM. High death rates in health care workers and teachers in Malawi. Transactions of the Royal Society of Tropical Medicine and Hygiene. 2002; 96: 34-7 